\title{
Acculturation and 4-Year Caries Increment Among Children of Foreign-Born Mothers in Sweden: A Register-Based Cohort Study
}

Anna Granlund ( $\sim$ anna.granlund87@gmail.com )

Karolinska Institute

Fernanda Cunha Soares

Karolinska Institute

Anders Hjern

Karolinska Institute

Göran Dahllöf

Karolinska Institute

Annika Julihn

Karolinska Institute

\section{Research Article}

Keywords: Acculturation, child, dental caries, ethnicity, human development index, length of stay; migration, socioeconomic status

Posted Date: December 17th, 2021

DOI: https://doi.org/10.21203/rs.3.rs-1118105/v1

License: (9) This work is licensed under a Creative Commons Attribution 4.0 International License. Read Full License

Version of Record: A version of this preprint was published at BMC Oral Health on April 7th, 2022. See the published version at https://doi.org/10.1186/s12903-022-02130-4. 


\section{Abstract}

Background: To study the association of maternal age upon arrival and length of residence in Sweden with the 4-year caries increment in their children between ages 3 and 7 years in relation to the human development index (HDI) of the maternal country of origin.

Method: This registry-based cohort study included all children born in 2000-2003 who resided in Stockholm County, Sweden, at age 3 years and who were followed up at age $7(n=65259)$.

Negative binomial regressions were used to analyze different models adjusted for sociodemographic factors.

Results: Children of foreign-born mothers, regardless of the HDI of the maternal country of origin, had a higher risk of caries increment between ages 3 and 7 years than children of Swedish-born mothers. The children of mothers who had arrived in Sweden from a low or medium HDI country, however, had a lower caries increment than the children of mothers arriving after age 7. Nearly half (44\%) of the children whose mothers arrived in Sweden at age $\geq 20$ years from a low HDI country had a caries increment compared to $22 \%$ of the children whose mothers had arrived in Sweden before 7 years of age. Furthermore, children whose mothers were born in a low HDI country and had resided in Sweden $\leq 19$ years had approximately 1.5 times higher risk of caries increment compared to children of mothers who had resided in Sweden for more than 20 years.

Conclusions: Caries increment in the children of foreign-born mothers was associated with the age of their mother when she arrived in Sweden and was lower when the mother had arrived before age 7 years. This indicates an intergenerational effect that carries over to the children and is greater the longer the mother has participated in Swedish dental healthcare.

\section{Background}

Global migration has increased dramatically. In 2019, the number of migrants reached an estimated 272 million globally, 51 million more than in 2010; international migrants comprised 3.5\% of the global population [1]. In Sweden, approximately $20 \%$ of the population have a foreign background [2]. Of these, over 800000 are children and adolescents who were born in another country or were born in Sweden to one or two foreign-born parents [3].

Sweden, like most developed countries, has seen a decrease in dental caries among children and adolescents in recent decades, but there are still groups of children with high caries experience [4]. A study in the north of Sweden reported that $58 \%$ of $4 y e a r o l d s$ with an immigrant background had dental caries compared to $15 \%$ of Swedish children [5]. Naturally, several socioeconomic factors may explain this difference. Low family income and maternal education, age at childbirth, single parenthood, and maternal health behaviors such as smoking and obesity during pregnancy have all been significantly linked to caries experience at 3 and 7 years of age [6, 7]. A recent study reported that, compared with children born to two Swedish parents, children in Sweden born to foreign-born parents from low and medium human development index [8] countries had the highest caries experience at 3 and 7 years of age, and from high HDI countries, a significantly higher caries experience. The study also found that children in families with a mixed background had a significantly higher risk of caries experience compared to children with two native Swedish parents [9]. Immigrants in Sweden with a non-European background report that they suffer from poor or very poor general health three to four times more often than the native Swedish population [10].

The migration process involves changes that will affect the lifestyle and health behaviors of those making their home in the new country. The process of adopting values and behaviors from another culture, and perhaps in time, also changing their beliefs, is referred to as acculturation [11]. A review of the oral health impacts of acculturation [12] concluded that information is limited and fragmented. Several studies have shown positive associations between acculturation indicators and use of dental services and better oral health among acculturated individuals [13]. On the other hand, acculturation may also promote behaviors that negatively affect oral health, such as the introduction of a more cariogenic diet [14].

Previous studies on acculturation in relation to dental caries in children of foreign-born parents have a cross-sectional design, they have lumped together immigrants from different parts of the world with different experiences and often lack information on 
the current socioeconomic situation [15]. Thus, the aim of this study was to investigate the association between maternal acculturation and caries increment between 3 and 7 years of age in children of foreign-born women in Sweden.

\section{Methods}

\section{Study design}

The present study is a longitudinal study and part of a register-based cohort study on development of dental caries in children between 3 and 7 years of age. Data sources were based on Swedish national registry data held by the Swedish National Board of Health and Welfare and by Statistics Sweden (SCB). Information on dental caries was collected from data sources at the Public Health Care Administration in Stockholm.

\section{Study population}

The study population was created from the population of child residents in Stockholm County, born in 2000-2003 (n = 83 147). The present study evaluated children who had been examined at 3 and 7 years of age in the Public Dental Service, by private practitioners, or at the Department of Dental Medicine, Karolinska Institutet. When the mother was foreign-born, participants were excluded from the study if there was no information on the maternal country of origin, age upon arrival in Sweden, or length of residence in Sweden. The final study sample comprised 63931 children who had had dental examinations at 3 and 7 years of age.

\section{Variables}

Information on age, year of arrival, and maternal country of origin was obtained from the Swedish Registry of Total Population at SCB. We classified countries into four categories for maternal nationality; the first category was Swedish-born mothers. For the other categories we used the HDI developed by the United Nations Development Program. It is a composite index of life expectancy, education level, and per capita income indicators. We used the HDI from 1999, the year before the children in this study were born (HDI 1999). The HDI cut-off values were as follows: low $=0.350-0.449$, medium $=0.550-0.699$, and high $\geq 0.700$ (Table 1).

From the database of The Swedish National Board of Health and Welfare, which maintains the Swedish Medical Birth Registry (MBR), we collected maternal age at childbirth (14-20 years; $21-25$ years; $26-30$ years; $31-35$ years; > 35 years) and family situation (single mothers, cohabitants). The SCB determines disposable household income using an algorithm that considers all household incomes reported to the Swedish Tax Agency, reduced by all taxes, and then divided by consumer units. The range of disposable household income in the study was used by first constructing quintiles and thereafter categorizing them as low (1st and 2 nd quintiles), medium (3rd quintile), and high (4th and 5th quintiles). Maternal educational level was classified as $\leq 12$ years and $>12$ years of education. The length of maternal residence in Sweden at childbirth was calculated as the difference between the child's birth year and the year that the mother had arrived in Sweden.

A proxy measure of acculturation was maternal age upon arrival in Sweden, classified as $<6,7-12,13-19$, and $\geq 20$ years of age.

\section{Dental caries}

Data on manifest caries lesions were collected from clinical and radiographic examinations. The decayed, extracted, and filled primary teeth (deft) index measured the severity of caries experience in children at 3 and 7 years of age. The definition of "manifest caries" as a lesion that clearly extends into the dentin was used in this study [16]. Radiographic examinations in the form of bitewings were only done given indications, to provide more extensive data on dentin caries lesions. The variable caries increment ( $\Delta$ deft) was defined as the difference between deft at age 3 and deft at age 7 years; the result was then dichotomized as "no caries increment" ( $\Delta$ deft $=0$ ) or "caries increment" ( $\Delta$ deft $\geq 1)$. No permanent teeth were included in the outcomes at 7 years of age.

\section{Statistical analyses}


STATA 14 for Windows (Stata Statistical Software; StataCorp LP; College Station, TX, USA) was used for data analysis. Descriptive analyses included relative and absolute frequencies. Differences between categorical variables were assessed using the chi-square test. We used negative binomial regressions to analyze 10 models, estimating incidence rate ratios (IRR) with $95 \%$ confidence intervals to assess the association between caries increment in children between 3 and 7 years of age (0: no risk group; 1: risk group). The analyzed models were:

(1) The HDI of the maternal country of origin and maternal age upon arrival in Sweden concurrently, using the Swedish-born population as a reference group (Figure 1).

(A) Evaluating mothers born in low HDI countries: (I.a) the model compares maternal age upon arrival in Sweden, with the mothers who arrived in Sweden before age 7 years as a reference group; (II.a) length of residence in Sweden of mothers, the with mothers who had lived in Sweden for 20 years or more as a reference group; (III.a) the model compares maternal age upon arrival in Sweden, with the mothers who arrived in Sweden before age 7 years as a reference group, adjusted by length of residence in Sweden of mothers.

(B) evaluating mothers born in medium HDI countries: (I.b) the model compares maternal age upon arrival in Sweden, with the mothers who arrived in Sweden before age 7 years as a reference group; (II.b) length of residence in Sweden of mothers, the with mothers who had lived in Sweden for 20 years or more as a reference group; (III.b) the model compares maternal age upon arrival in Sweden, with the mothers who arrived in Sweden before age 7 years as a reference group, adjusted by length of residence in Sweden of mothers.

(C) evaluating mothers born in high HDI countries: (I.c) the model compares maternal age upon arrival in Sweden, with the mothers who arrived in Sweden before age 7 years as a reference group; (II.c) length of residence in Sweden of mothers, the with mothers who had lived in Sweden for 20 years or more as a reference group; (III.c) the model compares maternal age upon arrival in Sweden, with the mothers who arrived in Sweden before age 7 years as a reference group, adjusted by length of residence in Sweden of mothers. All analyses were adjusted for sex of the child, maternal age, family situation, and income. We used the Bayesian Information Criterion (BIC) to assess the overall fit of a model and compare various models.

\section{Results}

Table 1

Countries of origin of the mothers of 63931 children who participated in the study.

\begin{tabular}{|lll|}
\hline \multicolumn{2}{|l|}{ Maternal country of origin } \\
\hline $\begin{array}{l}\text { Category } \\
\text { Non- }\end{array}$ & $\mathrm{n}$ & Country (\% in category) \\
\hline Immigrant & 593 & Sweden (100\%) \\
\hline High HDI & 2938 & $\begin{array}{l}\text { Western Europe (18.1\%), Nordic countries (53.4\%), southern Europe (6.9\%), North America (12.0\%), } \\
\text { Korea (9.6\%) }\end{array}$ \\
\hline Medium HDI & 8974 & $\begin{array}{l}\text { Eastern Europe (32.5\%), South America (12.5\%), China (2.2\%), Other Asia (51.9\%), Vietnam (0.5\%), } \\
\text { Oceania (0.4\%) }\end{array}$ \\
\hline Low HDI & 2516 & Africa (92.9\%), India (7.1\%) \\
\hline
\end{tabular}

$\mathrm{HDI}$, human development index; cut-offs: low $=0.350-0.449$, medium $=0.550-0.699$, high $\geq 0.700$

Of the 63931 eligible children who were evaluated, 23\% had a foreign-born mother. Table 1 presents the categories of maternal country of origin. At childbirth, $36 \%$ of the foreign-born mothers had resided in Sweden for 5 years or less while $25 \%$ had resided in Sweden for more than 15 years. Twenty percent of the foreign-born mothers came from low HDI countries and $62 \%$ from medium HDI countries. Compared with Swedish mothers, foreign-born mothers were more likely to have a lower income $(62 \%$ vs 
$31 \%$ ) and a lower educational level. They were also more likely to have given birth before they had reached 20 years of age (Table 2).

Table 2

Sociodemographic characteristics of mothers who resided in Stockholm County and gave birth in 2000-2003.

\begin{tabular}{|c|c|c|c|c|c|}
\hline \multirow[t]{2}{*}{ Variables } & \multirow[t]{2}{*}{ Category } & \multicolumn{2}{|c|}{$\begin{array}{l}\text { Swedish-born } \\
(\mathrm{n}=49503)\end{array}$} & \multicolumn{2}{|c|}{$\begin{array}{l}\text { Foreign-born } \\
(n=14428)\end{array}$} \\
\hline & & $\mathrm{n}$ & $\%$ & $\mathrm{n}$ & $\%$ \\
\hline \multirow[t]{3}{*}{ Income level $^{\star}$} & Low & 15286 & 31 & 8907 & 62 \\
\hline & Medium & 10725 & 22 & 2276 & 16 \\
\hline & High & 23271 & 47 & 3125 & 22 \\
\hline \multirow[t]{2}{*}{ Education level $^{*}$ (years) } & Low $(\leq 12)$ & 27686 & 56 & 5912 & 41 \\
\hline & High $(>12)$ & 21817 & 44 & 8516 & 59 \\
\hline \multirow[t]{2}{*}{ Family situation ${ }^{*}$} & Single & 8657 & 18 & 3336 & 23 \\
\hline & Cohabitant & 40846 & 82 & 11092 & 77 \\
\hline \multirow{5}{*}{$\begin{array}{l}\text { Maternal age at } \\
\text { childbirth }^{*} \text { (years) }\end{array}$} & $14-20$ & 700 & 1 & 435 & 3 \\
\hline & $21-25$ & 4787 & 10 & 2645 & 18 \\
\hline & $26-30$ & 16046 & 32 & 4474 & 31 \\
\hline & $31-35$ & 19128 & 39 & 4412 & 31 \\
\hline & $>35$ & 8842 & 18 & 2462 & 17 \\
\hline \multirow[t]{3}{*}{$\mathrm{HDI}$ category of maternal country of origin } & Low & - & - & 2938 & 20 \\
\hline & Medium & - & - & 8974 & 62 \\
\hline & High & - & - & 2516 & 18 \\
\hline \multirow[t]{4}{*}{ Mother's length of residence in Sweden at childbirth (years) } & $\leq 5$ & - & - & 5605 & 36 \\
\hline & $6-10$ & - & - & 3691 & 24 \\
\hline & $11-15$ & - & - & 2329 & 15 \\
\hline & $>15$ & - & - & 3922 & 25 \\
\hline
\end{tabular}

Table 3 presents the proportion of children who developed dental caries between 3 and 7 years of age in relation to maternal age upon arrival in Sweden and HDI of the maternal country of origin. Among mothers from a low or medium HDI country of origin, the proportion of 7-year-olds with a 4-year caries increment was lower when the mother had arrived before 7 years of age compared with arriving at an older age. Among mothers from a low HDI country of origin, $44 \%$ of children of mothers who had arrived in Sweden at age 20 years or older had a caries increment compared to 22\% whose mothers had arrived before age 7 . In contrast, this gradient did not occur in children of mothers from high HDI countries; that is, maternal age upon arrival in Sweden had non-significant bearing on the development of a caries increment in their children. 
Table 3

Caries increment between 3 and 7 years of age in relation to maternal background.

\begin{tabular}{|c|c|c|c|c|c|c|}
\hline \multirow[t]{3}{*}{ Maternal background } & \multicolumn{4}{|c|}{ Caries increment ${ }^{a}$} & \multirow{2}{*}{\multicolumn{2}{|c|}{ Total }} \\
\hline & \multicolumn{2}{|c|}{$\Delta$ deft $=0$} & \multicolumn{2}{|c|}{$\Delta$ deft $\geq 1$} & & \\
\hline & $\mathbf{n}$ & $\%$ & $\mathbf{n}$ & $\%$ & $\mathbf{n}$ & $\%$ \\
\hline \multicolumn{7}{|l|}{ Non-immigrant } \\
\hline Swedish-born & 40792 & 82.4 & 8711 & 17.6 & 49503 & 100 \\
\hline \multicolumn{7}{|c|}{ Immigrant (HDI of country of origin and age upon arrival in Sweden [years]) } \\
\hline \multicolumn{7}{|l|}{ Low HDI } \\
\hline $0-6$ & 90 & 78.3 & 25 & 21.7 & 115 & 100 \\
\hline $7-12$ & 61 & 64.2 & 34 & 35.8 & 744 & 100 \\
\hline $13-19$ & 241 & 59.5 & 164 & 40.5 & 405 & 100 \\
\hline$\geq 20$ & 1042 & 56.0 & 820 & 44.0 & 1862 & 100 \\
\hline Total & 1434 & 57.9 & 1043 & 42.1 & 2477 & 100 \\
\hline \multicolumn{7}{|l|}{ Medium HDI } \\
\hline $0-6$ & 509 & 66.2 & 260 & 33.8 & 769 & 100 \\
\hline $7-12$ & 442 & 58.1 & 319 & 41.9 & 761 & 100 \\
\hline $13-19$ & 738 & 47.7 & 809 & 52.3 & 1547 & 100 \\
\hline$\geq 20$ & 2948 & 51.0 & 2832 & 49.0 & 5780 & 100 \\
\hline Total & 4637 & 52.4 & 4220 & 47.6 & 8857 & 100 \\
\hline \multicolumn{7}{|l|}{ High HDI } \\
\hline $0-6$ & 691 & 75.9 & 219 & 25.1 & 910 & 100 \\
\hline $7-12$ & 168 & 81.2 & 39 & 18.8 & 207 & 100 \\
\hline $13-19$ & 167 & 70.2 & 71 & 29.8 & 238 & 100 \\
\hline$\geq 20$ & 1204 & 78.9 & 322 & 21.1 & 1526 & 100 \\
\hline Total & 2230 & 77.4 & 651 & 22.6 & 2881 & 100 \\
\hline
\end{tabular}

${ }^{a}$ Caries increment: The difference between deft at age 3 and deft at age 7 ( $\Delta$ deft) was dichotomized as "no caries increment" $(\Delta$ deft $=0$ ) or "caries increment" ( $\Delta$ deft $\geq 1)$. No permanent teeth were included in the outcomes at age 7 . HDI, human development index; cut-offs: low $=0.350-0.449$, medium $=0.550-0.699$, high $\geq 0.700$

Figure 1 shows that, independent of the HDI of the maternal country of origin, children of foreign-born mothers had a significantly higher risk of caries increment between ages 3 and 7 compared to children of Swedish-born mothers. More specifically, when compared to children of Swedish mothers, children whose mothers were born in low (IRR: $2.00 ; 95 \%$ Cl: 1.86-2.15) or medium (IRR: 2.33; 95\% Cl: 2.23-2.44) HDI countries and had arrived in Sweden at age 20 years or older had the highest risk of caries increment. The children of mothers from low and medium HDI countries exhibited a marked decrease in caries risk if the mothers had arrived before age 7 . The children of mothers born in medium HDI countries had an IRR of 1.57 for caries increment (95\% $\mathrm{Cl}: 1.39-1.78)$ while the IRRs of children of Swedish-born mothers and of children of mothers born in low HDI countries differed non-significantly. 
Table 4 shows the IRRs for the 4-year caries increment ( $\Delta$ deft $\geq 1$ between ages 3 and 7 years) in children of foreign-born mothers in relation to maternal age upon arrival and length of stay in Sweden. We used three models. Model I assessed the risk of caries increment, using as a reference children of mothers who had arrived in Sweden between 0 and 6 years of age, and adjusted for sex of the child, maternal age, family situation, and income. Children of mothers from both low and medium HDI countries who had arrived in Sweden after 13 years of age had around a 1.5 times higher risk of caries increment compared to children of mothers who had arrived before 7 years of age. Maternal age upon arrival in Sweden was unrelated to caries increment in children of mothers from high HDI countries, having no effect on caries risk. 
Table 4

Caries increment according to maternal age upon arrival and length of stay in Sweden.

\begin{tabular}{|c|c|c|c|c|c|c|c|c|c|}
\hline \multirow{5}{*}{$\begin{array}{l}\mathrm{HDI}^{\mathrm{a}} \text { of maternal country of } \\
\text { origin and age upon arrival in } \\
\text { Sweden (years) }\end{array}$} & \multicolumn{9}{|c|}{ Reference } \\
\hline & \multicolumn{3}{|c|}{$\begin{array}{l}\text { Maternal age upon arrival in } \\
\text { Sweden ( } 0-6 \text { years) }\end{array}$} & \multicolumn{3}{|c|}{$\begin{array}{l}\text { Maternal length of stay in } \\
\text { Sweden ( } \geq 20 \text { years) }\end{array}$} & \multirow{2}{*}{\multicolumn{3}{|c|}{$\begin{array}{l}\text { Maternal age upon arrival } \\
\text { in } \\
\text { Sweden ( } 0-6 \text { years) }\end{array}$}} \\
\hline & & & & & & & & & \\
\hline & \multirow[t]{2}{*}{$\mathrm{n}$} & IRR & \multirow[t]{2}{*}{$p$} & \multirow[t]{2}{*}{$\mathbf{n}$} & IRR & \multirow[t]{2}{*}{$p$} & \multirow[t]{2}{*}{$\mathrm{n}$} & IRR & \multirow[t]{2}{*}{$p$} \\
\hline & & $(95 \% \mathrm{Cl})$ & & & $(95 \% \mathrm{Cl})$ & & & $(95 \% \mathrm{Cl})$ & \\
\hline \multirow[t]{2}{*}{ Low HDI } & \multicolumn{3}{|c|}{ Model I(a) } & \multicolumn{3}{|c|}{ Model II(a) } & \multicolumn{3}{|c|}{ Model III(a) } \\
\hline & \multicolumn{3}{|c|}{$B I C^{\prime}=68.65$} & \multicolumn{3}{|c|}{$B I C^{\prime}=71.62$} & \multicolumn{3}{|c|}{$B I C^{\prime}=75.86$} \\
\hline \multirow[t]{2}{*}{$0-6$} & \multirow[t]{2}{*}{115} & \multirow[t]{2}{*}{1} & \multirow[t]{2}{*}{ - } & \multirow{2}{*}{$\begin{array}{l}1 \\
199\end{array}$} & 1.52 & \multirow[t]{2}{*}{0.011} & \multirow[t]{2}{*}{115} & 1 & - \\
\hline & & & & & $(1.10: 2.10)$ & & & & \\
\hline $7-12$ & 95 & 1.51 & 0.120 & 844 & 1.44 & 0.030 & 95 & 1.55 & 0.113 \\
\hline & & $(0.90: 2.54)$ & & & $(1.04: 1.99)$ & & & & \\
\hline $13-19$ & 405 & 1.65 & 0.021 & 241 & 1.56 & 0.016 & 405 & 1.73 & 0.036 \\
\hline & & $(1.08: 2.53)$ & & & $(1.09: 2.24)$ & & & & \\
\hline$\geq 20$ & 1 & 1.83 & 0.003 & 163 & 1 & - & 1 & 1.95 & 0.022 \\
\hline & & $(1.22: 2.74)$ & & & & & & & \\
\hline Medium HDI & Mod & I(b) & & Mod & $I I(b)$ & & Mod & III(b) & \\
\hline & $B I C^{\prime}$ & 82.60) & & $B I C^{\prime}$ & -72.97 & & $B I C^{\prime}$ & - 75.69 & \\
\hline $0-6$ & 769 & 1 & - & 4 & 1.30 & $<0.001$ & 769 & 1 & - \\
\hline & & & & & $(1.17: 1.45)$ & & & & \\
\hline $7-12$ & 761 & 1.25 & 0.008 & 2 & 1.29 & $<0.001$ & 761 & 1.22 & 0.027 \\
\hline & & $(1.06: 1.47)$ & & & $(1.15: 1.45)$ & & & & \\
\hline $13-19$ & 1 & 1.44 & $<0.001$ & 1 & 1.21 & 0.005 & 1 & 1.36 & 0.001 \\
\hline & & $(1.25: 1.65)$ & & & $(1.06: 1.37)$ & & & & \\
\hline$\geq 20$ & 5 & 1.43 & 0.002 & 1 & 1 & - & 5 & 1.31 & 0.018 \\
\hline & & $(1.26: 1.63)$ & & & & & & & \\
\hline High HDI & Mod & I(c) & & Mod & $I I(c)$ & & Moa & $I I I(c)$ & \\
\hline & $B I C^{\prime}$ & 50.41 & & $B I C^{\prime}$ & 51.93 & & $B I C^{\prime}$ & 57.76 & \\
\hline $0-6$ & 910 & 1 & - & 863 & 0.87 & 0.147 & 910 & 1 & - \\
\hline & & & & & $(0.72: 1.05)$ & & & & \\
\hline $7-12$ & 207 & 0.84 & 0.345 & 513 & 0.88 & 0.268 & 207 & 0.84 & 0.345 \\
\hline & & $(0.58: 1.21)$ & & & $(0.70: 1.10)$ & & & & \\
\hline $13-19$ & 238 & 1.25 & 0.286 & 321 & 1.03 & 0.810 & 238 & $\begin{array}{l}1.25 \\
(0.83 \cdot 187)\end{array}$ & 0.286 \\
\hline & & (0.83:1.87) & & & $(0.81: 1.32)$ & & & & \\
\hline
\end{tabular}




\begin{tabular}{|c|c|c|c|c|c|c|c|c|c|}
\hline \multirow{5}{*}{$\begin{array}{l}\mathrm{HDI}^{\mathrm{a}} \text { of maternal country of } \\
\text { origin and age upon arrival in } \\
\text { Sweden (years) }\end{array}$} & \multicolumn{9}{|c|}{ Reference } \\
\hline & \multicolumn{3}{|c|}{$\begin{array}{l}\text { Maternal age upon arrival in } \\
\text { Sweden ( } 0-6 \text { years) }\end{array}$} & \multicolumn{3}{|c|}{$\begin{array}{l}\text { Maternal length of stay in } \\
\text { Sweden ( } \geq 20 \text { years) }\end{array}$} & \multirow{2}{*}{\multicolumn{3}{|c|}{$\begin{array}{l}\text { Maternal age upon arrival } \\
\text { in } \\
\text { Sweden ( } 0-6 \text { years) }\end{array}$}} \\
\hline & & & & & & & & & \\
\hline & \multirow[t]{2}{*}{$\mathrm{n}$} & IRR & \multirow[t]{2}{*}{$p$} & \multirow[t]{2}{*}{$\mathrm{n}$} & \multirow{2}{*}{\multicolumn{2}{|c|}{$\begin{array}{l}\text { IRR } \\
(95 \% \mathrm{Cl})\end{array}$}} & \multirow[t]{2}{*}{$\mathrm{n}$} & \multirow{2}{*}{$\begin{array}{l}\text { IRR } \\
(95 \% \mathrm{Cl})\end{array}$} & \multirow[t]{2}{*}{$p$} \\
\hline & & (95\% & & & & & & & \\
\hline \multirow[t]{2}{*}{$\geq 20$} & \multirow{2}{*}{$\begin{array}{l}1 \\
526\end{array}$} & 1.05 & \multirow[t]{2}{*}{0.867} & \multirow{2}{*}{$\begin{array}{l}1 \\
158\end{array}$} & \multirow[t]{2}{*}{1} & \multirow[t]{2}{*}{-} & \multirow{2}{*}{$\begin{array}{l}1 \\
500\end{array}$} & \multirow{2}{*}{$\begin{array}{l}1.05 \\
(0.62: 1.77)\end{array}$} & \multirow[t]{2}{*}{0.867} \\
\hline & & $(0.62$ & & & & & & & \\
\hline
\end{tabular}

${ }^{\mathrm{a}} \mathrm{HDI}$, human development index; cut-offs: low $=0.350-0.449$, medium $=0.550-0.699$, high $\geq 0.700 ;$ BIC', Bayesian Information Criterion; In bold: the best model (smallest BIC'); Model I - adjusted: sex, maternal age at childbirth, family situation, income; Model II - adjusted: sex, maternal age at childbirth, family situation, income; Model III - adjusted: mother's length of stay in Sweden at childbirth, sex, maternal age at childbirth, family situation, income

Model II assessed the risk of caries increment in children in relation to maternal length of residence in Sweden with 20 years or more as a reference and adjusted for sex of the child, maternal age, family situation, and income. Children of mothers born in low HDI countries who had resided in Sweden for 19 years or less had around a 1.5 times higher risk of caries increment compared to children of mothers who had resided in Sweden for more than 20 years. Risk decreased to about 1.3 in children of mothers born in medium HDI countries. Children of mothers from high HDI countries had no increase in caries risk.

Model III presents the risk of caries increment in children of mothers who had arrived in Sweden between 0 and 6 years of age as reference, adjusted by maternal length of residence in Sweden, in addition to the other adjustments noted above. The risk of caries increment was significantly higher in children of mothers for medium HDI countries older than 7 years upon arrival in Sweden, whereas the risk for caries increment was highest in children of mothers from low HDI countries who had arrived in Sweden after 12 years of age.

Regardless of the HDI of the country of origin, the models with the best fit were the ones that took into account maternal age upon arrival in Sweden and were adjusted by sex of the child, maternal age, family situation, income.

\section{Discussion}

The results of the present study show that children of foreign-born mothers in Sweden from the various HDI countries had a higher risk of caries increment between 3 and 7 years of age than same-aged children of Swedish-born mothers. Further, the younger the mothers were upon arrival in Sweden, the lower the risk of caries increment in their children was when maternal country of origin had a low or medium HDI.

The main finding of the present study is that the age of the mothers upon arrival in Sweden is a main determinant of caries risk in their offspring, independent of the time they had lived in Sweden before childbirth. This suggests that maternal participation in the Swedish preventive dental health program has intergenerational effects that carry over to their offspring, with a greater effect the longer the mother has participated in this program. At the time when the parents of the children in this study were children themselves, they participated in a dental health program that highly valued pediatric oral health through a focus on prevention, biannual dental examinations, and treatment free of charge.

About $18 \%$ of children born in families with two Swedish parents developed dental caries between 3 and 7 years of age; all immigrant groups had a significantly higher caries increment. Immigrants in Sweden, and their children, have also been found to have higher risks of general health problems, including psychiatric morbidity $[17,18]$ and poor subjective health $[10]$. Several studies have reported higher caries experience in preschool children with immigrant background $[5,19,20]$. A cross-sectional study of caries experience in Denmark found that the mean caries experience was three to four times higher among 5- and 7-yearold children with non-Danish mothers than among children of Danish-born mothers [6]. In addition to socioeconomic factors, 
significantly fewer foreign-born parents brush their children's teeth twice daily with fluoride toothpaste [6], and a study on dietary transition among minority populations in the Nordic countries found a higher intake of sugary products among immigrant children aged 0-7 years [21]. In the new country, immigrants tend to adopt not only positive but also negative behaviors, which may lead to a worse health outcome than in their home countries [22]. Önal [23] found that the caries prevalence of Turkish children who were living in Turkey and had a low socio-economic status was lower than in Turkish children living in Germany or in German children; the deterioration in oral health after immigration was the result of adapting to western meals and dietary habits without improving oral hygiene.

We found that a higher proportion of children whose parental country of origin was a medium HDI country had a caries increment compared to when the parental country of origin was a low HDI country. This may seem somewhat contrary to findings reporting a gradient of health outcomes in children of immigrants related to increasing HDI of the country of origin [24, 25]. The HDI is a composite index of life expectancy, gross national product, and educational level of the population [26]. In a recent study on African countries, no difference in early childhood caries in 3-5-year-old children was found between low- and medium-income countries. It was concluded that child health and child oral health is more dependent on how society organizes itself and how it uses the resources rather than on wealth per se [27]. Most of the mothers in the medium HDI group came from eastern and central Europe where prevalence of early childhood caries is high and oral health priorities in national preventive policies are low [28].

Proxy measures of acculturation include ethnic identification, language skills, age at immigration, length of residence in the host country, and social affiliation $[12,13]$. The present study used age upon arrival in Sweden as a proxy measure of acculturation, but also adjusted for length of stay in Sweden in the analyses. Werneck et al. [29] also demonstrated that arrival in the new country at an early age is beneficial for the oral health of the offspring; their study among Portuguese-speaking immigrants in Canada found that children of mothers who were older than 22 when they arrived in Canada had a 2.36 times higher odds of early childhood caries compared to those whose mothers had arrived at a younger age. A cross-sectional study of 15-year-olds in Sweden found that those born in Sweden of immigrant parents or who had arrived before the age of 1 had a similar caries prevalence as non-immigrant adolescents, whereas children who had immigrated to Sweden after 7 years of age had a caries prevalence that was 2-3 times higher [30].

Berry [31] introduced the concept of acculturation strategies and suggested that this process has four possible outcomes: assimilation (when individuals do not wish to maintain their cultural identity and seek daily interaction with other cultures), separation (when individuals place a value on holding on to their original culture, and at the same time wish to avoid interaction with others), integration (when there is an interest in not only maintaining one's original culture but also interacting daily with other groups), or marginalization (when there is little possibility or interest in cultural maintenance and little interest in having relations with others). When using this approach to study oral health among Pacific immigrants to New Zealand, Schluter et al. [32] found that while Pacific children were more likely to have poorer oral health than their non-Pacific peers, differences in cultural alignment appeared to have only a relatively modest impact against the complex backdrop of individual, social, environmental, and political conditions. We previously showed that within each stratum of mothers from low and medium HDI countries, there is a gradient of an increasing proportion of children with a caries increment between 3 and 7 years of age among those of low family income [9].

One major advantage of register-based longitudinal studies is the low attrition rate. Over 4 years, only $14 \%$ of the participants were lost to follow-up, minimizing the risk of selection bias. In clinical randomized controlled trials on caries prevention, an attrition rate of $25 \%$ over 2 years in not uncommon, particularly in high-risk populations. Also, the quality of socioeconomic data is better than of self-reported data, since they are retrieved from tax returns with reports of income and national registries that record occupation, educational level, housing, and area of residence. A limitation of this study is that asylum seeking, and undocumented children were excluded since they are not included in the national registries used.

\section{Conclusion}

The present study shows that children of foreign-born mothers from countries of all HDI levels had an increased risk of caries increment between 3 and 7 years of age. The risk of caries increment was significantly lower in children whose mothers had arrived in Sweden from low and medium HDI countries before 7 years of age. This pattern was not seen in children of mothers

Page 10/14 
from high HDI countries. The persistence of disparities in the dental health of children of mothers arriving in Sweden at older ages suggests that universal dental health coverage may not be sufficient in this population for ensuring appropriate behaviors regarding diet and tooth brushing twice daily with fluoride toothpaste as well as utilization of primary and preventive care. This is particularly worrisome since the fluoride-based methods used in high-risk populations now seem ineffective [33]. Thus, a new clinical research agenda is needed to address this issue. We need to further explore possibilities of collaboration between pediatric healthcare and child dental care and methods of long-term support for immigrant families.

\section{Abbreviations}

HDI: Human Development Index; Cl: Confidence Interval; deft: decayed, extracted, filled, teeth; MBR: medical Birth Registry; OR: Odds Ratio; SCB: Statistics Sweden; IRR: incidence rate ratios; BIC Bayesian Information Criterion.

\section{Declarations}

\section{Ethics approval and consent to participate}

The ethical committee that approved the study (No. 2010/1563-31/1) was The Regional Ethics Review Board in Stockholm. This study used anonymized data from Swedish national Board of

Health and Welfare and Statistics Sweden (SCB) registers, Information on dental caries was collected from data sources at the Public Health Care Administration in Stockholm and thus informed consent could not be obtained.

\section{Consent for publication}

Not applicable.

\section{Availability of data and material}

The data that supports the findings of this study is available from the Swedish National Board and Welfare, restriction apply to the availability of these data, it was obtained under license and

therefor not publicly available. Information on dental caries was collected from data sources at the Public Health Care Administration in Stockholm. Questions or requests concerning this data is directed to author, Annika Julihn.

\section{Competing interests}

The authors declare no competing interests.

\section{Funding}

This study was commissioned and supported by Stockholm County Council and by grants from the Swedish Patent Revenue Research Fund. The funding source was not involved in data collection, analysis, or manuscript preparation

\section{Authors contributions}

AG, FCS, GD, and AJ contributed to the study design; AG, FCS, AH, GD and AJ performed the data acquisition and analysis; All authors participated in interpreting the result, reviewing drafts and approving the final version. All authors read and approved the final manuscript.

\section{Acknowledgments}

None.

\section{Author details:}


${ }^{1}$ Division of Orthodontics and Pediatric Dentistry, Department of Dental Medicine, Karolinska Institutet, Stockholm, Sweden; ${ }^{2}$ Department of Pediatric Dentistry, Eastman Institute, Folktandvården Stockholm AB, Stockholm, Sweden; ${ }^{3}$ Center for Pediatric Oral Health Research, Box 6031, 10231 Stockholm, Sweden; ${ }^{4}$ Clinical Epidemiology, Department of Medicine, Karolinska Institutet, Stockholm, Sweden; ${ }^{5}$ Centre for Health Equity Studies (CHESS), Stockholm University, Stockholm, Sweden; ${ }^{6}$ Center for Oral Health Services and Research, Mid-Norway, Trondheim, Norway

\section{References}

1. The UN Refugee Agency. Global Trends. Forced Displacement in 2019. Denmark: The UN Refugee Agency;2020. Available from: https://www.unhcr.org/5ee200e37.pdf. Accessed 01 June 2021.

2. Statistics Sweden. Number of foreign-born in Sweden. https://www.scb.se/hitta-statistik/sverige-i-siffror/manniskorna-isverige/utrikes-fodda/. Accessed 01 June 2021.

3. Statistics Sweden. Children and their Families. http://www.statistikdatabasen.scb.se/pxweb/sv/ssd/START_LE_LE0102_LE0102A/LE0102T15/table/tableViewLayout1/. Accessed 01 June 2021.

4. Jacobsson B, Koch G, Magnusson T, Hugoson A. Oral health in young individuals with foreign and Swedish backgrounds - a ten-year perspective. Eur Arch Paediatr Dent. 2011;12:151-8.

5. Stecksén-Blicks C, Hasslöf P, Kieri C, Widman K. Caries and background factors in Swedish 4-year-old children with special reference to immigrant status. Acta Odontol Scand. 2014;72:852-8.

6. Christensen LB, Twetman S, Sundby A. Oral health in children and adolescents with different socio-cultural and socioeconomic backgrounds. Acta Odontol Scand. 2010;68:34-42.

7. Julihn A, Soares FC, Hjern A, Dahllöf G. Socioeconomic Determinants, Maternal Health, and Caries in Young Children. JDR Clin Trans Res. 2018;3:395-404.

8. HDI - (Human Development Index) 1999. https://countryeconomy.com/hdi?year=1999. Accessed 01 June 2021.

9. Julihn A, Soares FC, Hjern A, Dahllöf G. Development level of the country of parental origin on dental caries in children of immigrant parents in Sweden. Acta Paediatr. 2021;110:2405-14.

10. Hjern A. Migration and public health: Health in Sweden: The National Public Health Report. 2012. Chapter 13. Scand J Public Health. 2012;40:255-67.

11. Abraído-Lanza AF, Armbrister AN, Flórez KR, Aguirre AN. Toward a theory - driven model of acculturation in public Health Research. Am J Public Health. 2006;96:1342-6.

12. Gao XL, McGrath CA. Review on the Oral Health Impacts of Acculturation. J Immigr Minor Health. 2011;2:202-13.

13. Dahlan R, Badri P, Saltaji H, Amin M. Impact of acculturation on oral health among immigrants and ethnic minorities: A systematic review." PLoS ONE. 2019;28;14.

14. Cruz GD, Shore R, Le Geros RZ, Tavares M. Effect of acculturation on objective measures of oral health in Haitian immigrants in New York City." J Dent Res. 2004;83:180-4.

15. Calvasina P, Gastaldo D, Quiñonez C, Muntaner C. Developing a Research Agenda on the Political Economy of Immigrants." J of Immigr Minor Health. 2018;20:759-61.

16. Pitts NB. Clinical diagnosis of dental caries: a European perspective. J Dent Educ. 2001;65:972-8.

17. Jablonska B, Lindberg L, Lindblad F, Hjern A. Ethnicity, socio-economic status and self-harm in Swedish youth: a national cohort study. Psychol Med. 2009;39:87-94.

18. Mock-Muñoz de Luna CJ, Vitus K, Torslev MK, Krasnik A, Jervelund SS. Ethnic inequalities in child and adolescent health in the Scandinavian welfare states: The role of parental socio-economic status - a systematic review. Scand J Public Health. 2019;47:679-89.

19. Hjern A, Grindefjord M. Dental health and access to dental care for ethnic minorities in Sweden. Ethn Health. 2000;5:23-32.

20. Wigen TI, Wang NJ. Caries and background factors in Norwegian and immigrant 5-year-old children. Community Dent Oral Epidemiol. 2010;38:19-28. 
21. Wändell PE. Population groups in dietary transition. Food Nutr Res. 2013;57.

22. Lara M,Gamboa C, Kahramanian MI, Morales LS, Bautista DEH. Acculturation and Latino health in the United States: A review of the literature and the sociopolitical context. Annu Revof Public Health. 2005;26:367-97.

23. Önal B. Kariesintensität bei Türkischen Kindern in Deutschland und in der Türkei. Schweiz Monatsschr Zahnmed. 1992;102:1333-6.

24. Juárez SP, Hjern A. The weight of inequalities: Duration of residence and offspring's birthweight among migrant mothers in Sweden. Soc sci Medno. 2017;175:81-90.

25. Elrod J, Schiestl CM, Mohr C, Landolt MA. Incidence, severity and pattern of burns in children and adolescents: An epidemiological study among immigrant and Swiss patients in Switzerland. Burns. 2019;45:1231-41.

26. Dinsa GD, Goryakin Y, Fumagalli E, Suhrcke M. Obesity and socioeconomic status in developing countries: a systematic review. Obes Rev. 2012;13:1067-79.

27. Folayan MO., Tantawi ME, Nourhan MA, Al-Batayneh OB, Schroth RJ , Castillo JL et al. Association between early childhood caries and poverty in low and middle income countries. BMC Oral Health. 2020;20:8.

28. Malkiewicz K, Malkiewicz E, Eaton KA, Widström E. The healthcare system and the provision of oral healthcare in European Union Member States. Part 6: Poland. Br Dent J. 2016;221:501-7.

29. Werneck RI, Lawrence HP, Kulkarni GV, Locker D. Early childhood caries and access to dental care among children of Portuguese-speaking immigrants in the city of Toronto. J Can Dent Assoc. 2008;74:805.

30. Jacobsson B, Wendt LK, Johansson I. Dental caries and caries associated factors in Swedish 15-year-olds in relation to immigrant background. Swed Dent J. 2005;29:71-9.

31. Berry JW. Immigration, acculturation and adaptation. Appl. Psychol. 2008;46:5-68.

32. Schluter PJ, Kanagaratnam S, Taylor S, Tautolo ES. Acculturation and its impact on the oral health status of Pacific children in New Zealand: findings from the Pacific Islands Families study. J Public Health Dent. 2017;77:225-33.

33. Anderson M, Dahllöf G, Twetman S, Jansson L, Bergenlid AC, Grindefjord M. Effectiveness of Early Preventive Intervention with Semiannual Fluoride Varnish Application in Toddlers Living in High-Risk Areas: A Stratified Cluster-Randomized Controlled Trial. Caries Res. 2016;50:17-23.

\section{Figures}




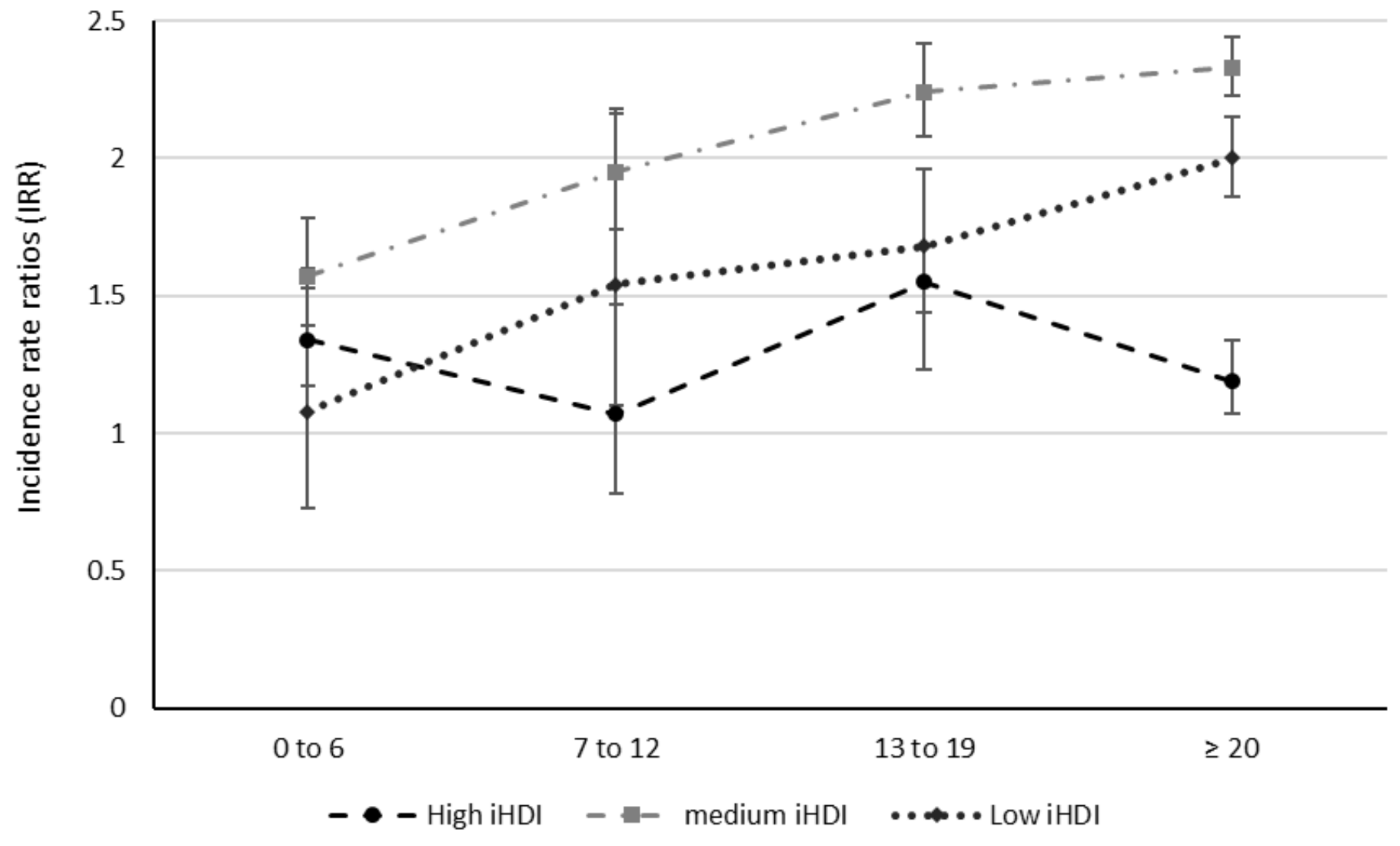

Figure 1

Association (incidence rate ratio) of age of foreign-born mothers upon arrival in Sweden and their children's risk of developing a caries increment between ages 3 and 7 years with the HDI of the maternal country of origin using Swedish-born mothers as a reference. Logistic regression analyses were adjusted for length of maternal residence in Sweden, sex of child, maternal age at childbirth, family situation, and income (HDI, human development index; cut-offs: low $=0.350-0.449$, medium $=0.550-0.699$, high $\geq 0.700$ 